\title{
Effects of an educational technology application in the early detection of breast cancer
}

\author{
Efeitos da aplicação de uma tecnologia educativa na detecção precoce do câncer de mama
}

Anna Paula Sousa da Silva ${ }^{1}$, Helanno Gomes Alexandre ${ }^{2}$, Paulo César de Almeida ${ }^{3}$, Lorena Barbosa Ximenes ${ }^{1}$, Ana Fátima Carvalho Fernandes ${ }^{1}$

Objective: to evaluate the effects of an educational technology application on the early detection of breast cancer. Methods: a quasi-experimental study of the Knowledge, Attitude and Practice survey type. The sample consisted of 294 women in two groups: Experimental Group and Control Group. Results: 9.5\% of the participants of the experimental group before the educational intervention presented adequate knowledge and after the application of the technology there was an increase of $89.2 \%$. Regarding the attitude, the experimental group in the early detection of breast cancer before the intervention had $69.9 \%$ and after the application was $89.2 \%$. Only $61.2 \%$ of the participants presented adequate practice and, after applying the technology, this number rose to $93.7 \%$. Conclusion: the knowledge, attitude, and practice of early breast cancer screening of women who participated in the applicability of the educational manual were different from those of women who did not participate.

Descriptors: Breast Neoplasms; Women's Health; Technology Educational.

Objetivo: avaliar os efeitos da aplicação de uma tecnologia educativa acerca da detecção precoce do câncer de mama. Métodos: estudo quase-experimental do tipo inquérito Conhecimento, Atitude e Prática. A amostra foi composta de 294 mulheres distribuídas em dois grupos: Grupo Experimental e Grupo Controle. Resultados: 9,5\% das participantes do grupo experimental antes da intervenção educativa apresentaram conhecimento adequado e após a aplicação da tecnologia houve um aumento para 89,2\%. Em relação à atitude, na detecção precoce do câncer de mama o grupo experimental antes da intervenção apresentava 69,9\% e após a aplicação passou para $89,2 \%$. Apenas $61,2 \%$ das participantes apresentaram prática adequada e após a aplicação da tecnologia este número passou para 93,7\%. Conclusão: 0 conhecimento, a atitude e a prática sobre os exames de detecção precoce do câncer de mama das mulheres que participaram da aplicabilidade do manual educativo mostraram-se diferentes daqueles das mulheres que não participaram.

Descritores: Neoplasias da Mama; Saúde da Mulher; Tecnologia Educacional.

\footnotetext{
${ }^{1}$ Universidade Federal do Ceará. Fortaleza, CE, Brazil.

${ }^{2}$ Fanor | DeVry Brasil. Fortaleza, CE, Brazil.

${ }^{3}$ Universidade Estadual do Ceará. Fortaleza, CE, Brazil. 


\section{Introduction}

Breast cancer is a serious public health problem worldwide, not only because of the increasing number of cases diagnosed each year but also because of the financial investment needed to address the issues of diagnosis and treatment ${ }^{(1)}$.

In most countries, this disease has had high and increasing incidence. There are $60.0 \%$ of the cases registered in the world in developing countries, drawing attention to the need to implement actions for health promotion, prevention, diagnosis and early treatment ${ }^{(1-3)}$.

The key to breast cancer control is the secondary prevention with the early detection of the disease. No matter how wide the coverage of curative interventions may be. This disease can only be controlled if measures such as early screening tests are implemented, able to detect it in its early stages ${ }^{(4)}$.

The lack of knowledge of early detection of breast cancer can lead to the risk of complications. The people's awareness of cancer and the stimulation of behavioral changes and research are fundamental actions for the initial prevention of cancer. This finding reinforces the importance of continuing education, so health professionals can competently develop the actions proposed by public cancer control policies ${ }^{(5-7)}$.

Currently, proposals for health education have been based on concepts that proclaim the autonomy of the individual, their participation, and agency as the author of their choices. The possibility of applying methods, tactics, and strategies to stimulate empowerment, self-management and self-care seem to predominate in the articulations between health education and health promotion. Health education in breast cancer, especially in early detection, is a process of formation, mediated by experiences, values, attitudes, knowledge and practices, considering the human being as a historical subject with possibilities of intervening in the reality ${ }^{(8)}$.

The use of educational technology with the objective of developing or strengthening capacities favors the promotion of health and makes the participants multipliers of actions. Hence the need to create and adopt informative and educational strategies with the purpose of disseminating and expanding knowledge, providing a basis for the exercise of self-care.

Given this context, this investigation was developed with the objective of evaluating the effects of the application of educational technology on the early detection of breast cancer.

\section{Methods}

This is a quasi-experimental study, composed of an experimental group (EG) and non-equivalent control group (CG), associated with the knowledge, attitude and practice survey for mammography and clinical examination of the breasts, performed with women attended at a Basic Health Unit located in a suburban neighborhood.

In this Basic Health Unit, there is monthly gynecological care performed (about 200 visits/month). The women interviewed were approached when they were waiting for their gynecological prevention consultation in the months destined for the collection of the research data.

The sample was calculated according to the following values: a significance level of 5.0\% $\left(t_{5 \%}=1.96\right)$, an absolute sample error of $4.0 \%$ and a $P$ proportion equal to $50.0 \%$ of women with adequate knowledge of the early detection of breast cancer. When replacing the values in the formula, there were: $\mathrm{t}_{5 \%}=1,96 ; \mathrm{P}=50.0 \% ; \mathrm{Q}=50.0 \%, \mathrm{e}=4.0 \%$ and $\mathrm{n}=400$. A total of 240 women were found. Considering probable losses of information and/or forms, 54 women were included in the sample (slightly more than 20.0\%), which resulted in a sample of 294 women distributed in two groups, 147 women in the Experimental Group before intervention ( EGa) and 147 women for the Control Group before the intervention (CGa). In the return visit after the educational intervention, there was a total of 111 participants of the Experimental Group after the Intervention (EGd) and the control group af- 
ter the intervention (CGd), there were 75 women to perform this phase.

The distribution of women between the EG and CG in the first phase was chosen on the day of the week in which they went to the gynecological prevention consultation, during the data collection period between April and June 2012 (women who attended the second and fourth quarters composed the EG, those who attended the Tuesdays and Thursdays were the CG), being held by drawing lots.

The discontinuation criteria of the study were: women's withdrawal from participating in the study, after starting the collection; Non-attendance to the return visit, hindering to continue collecting data.

The intervention was the application of an educational manual, created by two research nurses in the Oncology area, which formalized the consent for its use and adaptation to this research.

It is a manual of guidelines for mastectomized women, with 51 pages distributed in pre-textual elements; (From the breast cancer explanation, diagnostic exams, mastectomy, treatment, rehabilitation, diet and even the discussion about rights and legislation); and post-textual. The texts were elaborated in simple language, comprehensible to the reader, and validated by judges specializing in the subject ${ }^{(9)}$.

In this study, the first two chapters were used that correspond to: "Knowing what breast cancer is" contains explanations on the subject, and "Knowing more about the subject," presenting pertinent information about the screening tests for breast cancer.

For the collection of data, a form of the type of knowledge, attitude, and practice was used (the form that identifies the knowledge, the attitude and the practice of the studied population on mammography and the clinical examination of the breasts).

The EG women participants had the opportunity to attend an educational session, using the educational manual, shortly after completing the survey knowledge, attitude and practice and later they took the manual to perform reading at home, until the return visit.
Secondly, in the return visit, with a minimum date of 30 working days after the consultation and application of the educational intervention, the women participants, both from the EG and the CG, returned to the basic health unit to receive the result of the gynecological prevention exam and for completing the post-intervention form.

The knowledge, attitude and practice of the tests were assessed as follows: (1) adequate knowledge, when the woman reported having heard of early breast cancer screening exams (clinical examination of the breasts and mammography) and knew how these tests were performed and also how they were used for the early detection of the disease; (2) inadequate knowledge, when the woman said that she had never heard of the examinations or had heard, but could not quote it, how they should be performed, or what they were for; (3) adequate attitude when the woman reported that she should perform the tests and presented the early detection of breast cancer as the reason for performing these tests and/or when she referred as a reason to be a routine examination or desire to know if she was okay with it (self-care) - there was only considered an appropriate attitude when, at the same time, she had adequate knowledge of the examinations; (4) inadequate attitude: when the woman reported that she should not take the tests and did not have other motivations for the examination other than the early detection of breast cancer or self-care; (5) adequate practice in the clinical examination when the woman reported that she performed this examination annually and, the mammography, when the woman reported performing it annually or at least every 2 years. It is worth noting, as recommended ${ }^{(1)}$, that the mammography was valid for those over 35 years old; (6) inadequate practice when the woman had performed these tests in periodicities other than those mentioned above or had never performed them.

Data were compiled and analyzed using the statistical program Statistical Package for the Social Sciences, version 21.0. In the first part of this study, the socioeconomic and demographic characteristics 
of the participating groups were presented before the application of the educational intervention to demonstrate equivalence of the two populations. Next, the main aspects of the 294 women, before the educational intervention (EG and CG), were presented, regarding their knowledge, their attitudes, and practices of methods of early detection of breast cancer.

The exploratory analysis involved descriptive statistical tests, with the construction of distributions of absolute and relative frequencies. Continuous variables were expressed as a mean and standard deviation, and categorical variables were expressed as frequencies and percentages. Differences between the means of the studied groups were observed through Student's t-test; Continuous variables were assessed by the Student $t$ test or Mann-Whitney test. The categorical variables were analyzed by the Pearson chisquare test. For all analyses, $p$-value $<0.05$ was considered statistically significant.

The study complied with the formal requirements contained in the national and international regulatory standards for research involving human beings.

\section{Results}

The total study sample $(\mathrm{n}=294)$ was divided into two groups EGa (n=147) and CGa (n=147) in the first phase and two groups EGd $(n=111)$ and CGd $(n=75)$ in the second phase of the research.

Baseline characteristics of the sociodemographic variables were compared to guarantee that the two groups ( $E G$ and $C G$ ) were not different at baseline: age 35.97 years old for $E G$ and 37.03 for $C G(p=0.962)$; years of study 10.56 for the EG and 10.54 for the CG ( $p=0.955)$; family income of 687.81 for the EG and 755.06 for the CG $(p=0.305)$. There was no significant difference between the two groups, reinforcing that the groups were homogeneous and the proposal of educational intervention, with the application of the educational manual to the groups, could then be performed to verify the effectiveness of the education strategy in health promotion of breast health through the early detection of breast cancer. As can be seen in Table 1, there were no statistically significant differences between the groups at the beginning of the study on these variables.

Table 1 - Comparison of the average of the variables age, income and years of education according to the groups

\begin{tabular}{lccc}
\hline Group & Average & $\begin{array}{c} \pm \text { Average } \\
\text { standard error }\end{array}$ & $\mathbf{p}^{*}$ \\
\hline Age & & & 0.962 \\
Experimental & 35.97 & 1.040 & \\
Control & 37.03 & 0.992 & 0.955 \\
Education (years) & & & \\
Experimental & 10.56 & 0.240 & 0.305 \\
Control & 10.54 & 0.265 & \\
Family income (minimum salary) & & & \\
Experimental & 687.81 & 37.057 & \\
Control & 755.06 & 53.906 & \\
*Teste tde Student & & &
\end{tabular}

According to the results of the total sample of the study, there was a prevalence of the following variables: age group between 41 and 72 years old, $n=112$ (38.1\%) of the total, $n=56$ (38.1\%) for EG with $n=56$ (38.1\%) for CG; Marital/stable union, with $\mathrm{n}=196$ $(66.7 \%)$ of the total, with $n=98(66.7 \%)$ for $E G$ and $\mathrm{n}=98(66.7 \%)$ for CG; Length of education from 12 to 15 years of study $n=124 ;(42.2 \%)$, with $n=63$ (42.9\%) for EG and $n=61$ (41.5\%) for CG. Regarding the occupation, $n=131$ (44.6\%) women reported being unemployed, $n=62$ (42.2\%) for EG and $n=69$ (46.9\%) for CG. They reported monthly family income up to a minimum wage of $n=182$ (61.9\%) women, with $n=96$ (65.3\%) for EG and $n=86$ (58.5\%) for CG. The Catholic religion was prevalent, with $n=180$ (61.2\%), with $\mathrm{n}=79(53.7 \%)$ for $\mathrm{EG}$ and $\mathrm{n}=101$ (68.7\%) for CG (Table 2). 
Table 2 - Distribution of participants regarding socioeconomic and demographic characteristics, $n=147$

\begin{tabular}{|c|c|c|c|c|}
\hline \multirow[b]{2}{*}{ Characteristics } & \multicolumn{3}{|c|}{ Group } & \multirow[b]{2}{*}{$\mathbf{p}^{*}$} \\
\hline & $\begin{array}{c}\text { Experimental } \\
\text { n (\%) }\end{array}$ & $\begin{array}{l}\text { Control } \\
\text { n (\%) }\end{array}$ & $\begin{array}{l}\text { Total } \\
\text { n (\%) }\end{array}$ & \\
\hline Age group (years old) & & & & 0.835 \\
\hline $18-30$ & $55(37.4)$ & $51(34.7)$ & $106(36.0)$ & \\
\hline $31-40$ & $36(24.5)$ & $40(27.2)$ & $76(25.9)$ & \\
\hline $41-72$ & $56(38.1)$ & $56(38.1)$ & $112(38.1)$ & \\
\hline Marital status & & & & 1.0 \\
\hline Without a partner & $49(33.3)$ & 49 (33.3) & $98(33.3)$ & \\
\hline With a partiner & $98(66.7)$ & $98(66.7)$ & $196(66.7)$ & \\
\hline Education (years) & & & & 0.838 \\
\hline From 3 to 7 & $26(17.7)$ & $30(20.4)$ & $56(19.0)$ & \\
\hline From 8 to 11 & $58(39.6)$ & $56(38.1)$ & $114(38.8)$ & \\
\hline From 12 to 15 & $63(42.9)$ & $61(41.5)$ & $124(42.2)$ & \\
\hline Occupation & & & & 0.123 \\
\hline Seamstress & $28(19.0)$ & $21(14.3)$ & 49 (16.7) & \\
\hline Unemployed & $62(42.2)$ & $69(46.9)$ & $131(44.6)$ & \\
\hline Student & $6(4.1)$ & $1(0.7)$ & $7(2.4)$ & \\
\hline Work out & $15(10.2)$ & $24(16.3)$ & $39(13.3)$ & \\
\hline Others & $36(24.5)$ & $32(21.8)$ & $68(23.0)$ & \\
\hline \multicolumn{2}{|c|}{ Income (minimum salary) } & & & 0.486 \\
\hline Up to 1 & $96(65.3)$ & $86(58.5)$ & $182(61.9)$ & \\
\hline From 1,1 to 2 & $36(24.5)$ & 43 (29.3) & $79(26.9)$ & \\
\hline From 2,1 to 10 & $15(10.2)$ & $18(12.2)$ & $33(11.2)$ & \\
\hline Religion & & & & 0.031 \\
\hline Catholic & $79(53.7)$ & $101(68.7)$ & $180(61.2)$ & \\
\hline Protestant & $51(34.7)$ & $34(23.1)$ & 85 (28.9) & \\
\hline Others & $17(11.6)$ & $12(8.2)$ & $29(9.9)$ & \\
\hline
\end{tabular}

Table 2 shows that the EG and CG were similar since there was no statistically significant association between most of the sociodemographic variables, since the results obtained in both groups did not differ among themselves.

Their similarity was related to age $(\mathrm{p}=0.835)$, marital status $(\mathrm{p}=1.0)$, education $(\mathrm{p}=0.838)$, occupation ( $\mathrm{p}=0.123)$, monthly family income $(\mathrm{p}=0.486)$.

The two groups of women studied differed only statistically from religion $(\mathrm{p}=0.031)$ but did not represent a significant characteristic for comparison between groups.

In Table 3, there is a comparison between the EG and CG groups before and after the educational intervention regarding the degree of knowledge, attitude and practice, in which there was a significant statistical difference in the group EGa X EGd.

By evaluating the participants' knowledge, by analyzing the previous variables, it can be observed that 131 women distributed in CGa $\mathrm{n}=18(12.2 \%)$, CGd $n=9$ (12.0\%), EGa $n=14$ (9.5\%) and EGd $n=99$ $(89.2 \%)$ presented adequate knowledge in the early detection tests for breast cancer.

Table 3 - Comparison between Knowledge, Attitude, and Practice of the early detection of breast cancer in the groups participating in the study

\begin{tabular}{|c|c|c|c|c|c|c|c|c|c|}
\hline \multirow[b]{2}{*}{ Variables } & \multicolumn{9}{|c|}{ Grupos } \\
\hline & $\begin{array}{c}\text { CGa } \\
\text { n(\%) }\end{array}$ & $\begin{array}{c}\text { EGa } \\
\text { n(\%) }\end{array}$ & $\mathbf{p}^{*}$ & $\begin{array}{c}\text { CGd } \\
\text { n(\%) }\end{array}$ & $\begin{array}{c}\text { EGd } \\
\text { n(\%) }\end{array}$ & $\mathbf{p}^{*}$ & $\begin{array}{c}\text { EGa } \\
\text { n(\%) }\end{array}$ & $\begin{array}{c}\text { EGd } \\
\text { n(\%) }\end{array}$ & $\mathbf{p}^{*}$ \\
\hline Knowledge & & & 0.454 & & & $<0.001$ & & & $<0.001$ \\
\hline Suitable & $18(12.2)$ & $14(9.5)$ & & $9(12.0)$ & 99 (89.2) & & $14(9.5)$ & $99(89.2)$ & \\
\hline Inappropriate & $129(87.8)$ & $133(90.5)$ & & $66(88.0)$ & $12(10.8)$ & & $133(90.5)$ & $12(10.8)$ & \\
\hline Attitude & & & $<0.001$ & & & $<0.001$ & & & $<0.001$ \\
\hline Proper & $128(87.1)$ & $100(69.0)$ & & $12(16.0)$ & $99(89.2)$ & & $100(69.9)$ & 99 (89.2) & \\
\hline Inadequate & 19 (12.9) & $45(31.0)$ & & $63(84.0)$ & $12(10.8)$ & & $45(31.0)$ & $12(10.8)$ & \\
\hline Practice clinical examination & & & 0.025 & & & $<0.001$ & & & $<0.001$ \\
\hline Proper & $108(73.5)$ & $90(61.2)$ & & $8(10.6)$ & 104 (93.7) & & $90(61.2)$ & $104(93.7)$ & \\
\hline Inadequate & $39(26.5)$ & $57(38.8)$ & & $67(89.4)$ & $7(6.3)$ & & $57(38.8)$ & $7(6.3)$ & \\
\hline
\end{tabular}


It is noteworthy that among the participants of the experimental group, it was observed that before the application of the educational intervention, only 9.5\% of the participants presented adequate knowledge and after the application of the educational manual there was an increase of $89.2 \%$. Due to its similarity with the experimental group before the manual, the control group presented only $12.2 \%$ of adequate knowledge. There was a statistically significant difference in the crosses between the groups CGd X EGd ( $p<0.001)$, EGa X EGd ( $p<0.001)$, presenting different results. At the cross between CGa X EGa $(\mathrm{p}=0.454)$, the similarity between the two groups is confirmed, since there was no significant difference between them, proving the similarity existing before the educational intervention and the effectiveness of the educational strategy.

Therefore, it is observed in Table 3 that 327 women (CGa n=128 (87.1\%), CGd n=12 (16.0\%), EGa $\mathrm{n}=100(69.9 \%)$ and $\mathrm{EGd} \mathrm{n}=99.2 \%)$ presented adequate attitude regarding the exams of early detection of breast cancer.

There was a statistically significant association between the crosses of the groups CGa $\mathrm{X}$ EGa $(p<0.001)$, CGd X EGd $(p<0.001)$, EGa X EGd $(p<0.001)$, presenting different results regarding the attitude of the participants to the context of the exams of early detection of breast cancer, demonstrating that although there was a significant association at the crossing of the CGa X EGa groups, the proportions found at the post-intervention crosses were larger for the group participants.

Clinical examination of the breasts was adequate in 302 participants, CGa $n=108$ (73.5\%), CGd $\mathrm{n}=8(10.6 \%)$, EGEa $\mathrm{n}=90$ (61.2\%) and EGD $\mathrm{n}=104$ (93.7\%). In this analysis, as quoted the practice regarding this examination was considered adequate when the woman performed it annually. It is observed that before the application of the educational intervention, only $61.2 \%$ of the participants presented adequate practice and after applying the manual this number went to $93.7 \%$. There was a statistically significant association at the crossings between the CGa X EGa ( $p=0.025)$; CGd X EGd ( $p<0.001)$, EGa X EGd $(p<0.001)$ because they presented different results regarding the practice of this exam. Although there was a significant association at the crossing of the CGa X EGd groups, the proportions found at the post-intervention crosses were larger for the participant group.

The practice of mammography could not be evaluated due to the short period of the research because this examination takes the time to perform and independent of the educational intervention performed for short term observation.

\section{Discussion}

Although some differences between the groups were statistically significant, all tendencies pointed in the same direction: better scores in the EGd compared to the CGd. Programs to prevent mortality or early diagnosis of cancer find their basis in the long duration of the health promotion phase $\mathrm{e}^{(10-11)}$.

Even with advances in diagnostic techniques, clinical breast exams still play a prominent role in the secondary prevention of breast neoplasms ${ }^{(11-12)}$. By a low-cost examination, the early diagnosis can be obtained, raising the rate of cure and increasing the survival of patients with breast cancer.

Several factors may have influenced the low knowledge about methods of early detection of breast cancer. A study shows that the relationship between education and clinical examination of the breasts was statistically significant for the knowledge regarding this examination ${ }^{(11-12)}$. It was observed that women with nine years of education or more were more frequently exposed to clinical examination of the breasts than women who studied for up to four years. Age also appeared to be related to a greater opportunity to receive a clinical examination of the breasts: younger women were examined in greater number than the older women ${ }^{(13-14)}$. 
Different cases of social and cultural barriers impede patients' access to programs for the early detection and treatment of breast cancer.

The prevalence of clinical breast examination showed a statistically significant linear trend $(\mathrm{p}=0.001)$, as the number of combined risk factors increased. Regarding the "mammography in life" and "gynecological consultation in the last year," there was a statistically significant increase in their prevalence with the increase in associated risk factors $(p<0.001$ for both) ${ }^{(15)}$.

Periodic recommendations and accurate teaching on methods for early detection of breast cancer help increase the number of women who perform such methods ${ }^{(16)}$.

The practice of the exams may be associated with the behavior of health professionals, general or trained nurses during the gynecological consultations of these women. During the preventive examination, not all women have their breasts clinically examined and/or the mammogram requested by the professional who performed the consultation ${ }^{(17)}$.

One of the limitations of this study was that the research was carried out in a short time, besides the fact that the information on the accomplishment of the clinical examination of the breasts and the mammography was obtained by interview, subject to the bias of memory and information leading to the possibility of a new study.

\section{Conclusion}

Knowledge, attitude, and practice about early breast cancer screening exams for women who participated in the applicability of the educational manual were different from those women who did not participate.

\section{Collaborations}

Silva APS contributed in designing the project, collecting, analyzing and interpreting the data and writing the article. Alexandre HG, Almeida PC and Ximenes LB contributed to the analysis, interpretation of the data and writing of the article. Fernandes AFC contributed in the relevant critical analysis of the content, essay of the article and final approval of the version to be published.

\section{References}

1. Instituto Nacional do Câncer (BR). Estimativa 2016. Incidência de Câncer no Brasil. Síntese de resultados e comentários [Internet]. 2016 [citado 2016 nov. 21]. Disponível em: http://www.inca. gov.br/estimativa/2016/index.asp?ID=2

2. Rocha-Brischiliari SC, Oliveira RR, Andrade L, Brischiliari A, Gravena AAF, Carvalho MDB, et al. The rise in mortality from breast cancer in young women: trend analysis in Brazil. PLoS One [Internet]. 2017 [cited 2017 Mar. 25]; 12(1):1-13. Available from: http://journals.plos. org/plosone/article/file?id=10.1371/journal. pone $0168950 \&$ type $=$ prin table

3. Moraes DC, Almeida AM, Figueiredo EN, Loyola EAC, Panobianco MS. Opportunistic screening actions for breast cancer performed by nurses working in primary health care. Rev Esc Enferm USP. 2016; 50(1):14-21.

4. Porto MAT, Teixeira LA, Silva RCF. Aspectos históricos do controle do câncer de mama no Brasil. Rev Bras Cancerol. 2013; 59(3):331-9.

5. Oliveira RDP, Santos MCL, Moreira CB, Fernandes AFC. Detection of breast cancer: knowledge, attitude, and practice of family health strategy women. J Cancer Educ [Internet]. 2017 [cited 2017 Mar. 25];11(1):16. Available from: https://link.springer.com/ article/10.1007\%2Fs13187-017-1209-4 
6. Cavalcante SAM, Silva FB, Marques CAV, Figueiredo EM, Gutiérrez MGR. Ações do enfermeiro no rastreamento e diagnóstico do câncer de mama no Brasil. Rev Bras Cancerol. 2013; 59(3):459-66.

7. Bertocchi FM, Fernandes BM, Almeida MIG, Freitas SC, Paiva CCN, Paula EA. Professional conduct during breast and uterine/cervical cancer screening consultations. Rev Rene. 2014; 15(6):973-9.

8. Bagnato MHS, Missio L, Renovato RD, Bassinello GPH. Práticas educativas em saúde: da fundamentação à construção de uma disciplina curricular. Esc Anna Nery. 2009; 13(3):651-6.

8. Oliveira MS, Santos MCL, Almeida PC, Panobianco MS, Fernandes AFC. Evaluation of an educational handbook as a knowledge-acquisition strategy for mastectomized women. Rev Latino-Am Enfermagem. 2012; 20(4):668-78.

9. Ministério da Saúde (BR). Manual Operacional para Comitês de Ética em Pesquisa. Brasília: Ministério da Saúde; 2012.

10. Azevedo AC, Canella EO, Djahjah MCR, Koch HA. Conduta das funcionárias de um hospital na adesão ao programa de prevenção do câncer de mama. Radiol Bras. 2012; 45(4):215-8.

11. Antoine C, Ameye L, Paesmans M, Rozenberg S. Systematic review about breast cancer incidence in relation to hormone replacement therapy use. J Climacteric. 2014; 17(2):116-32.
12. Plecha D, Salem N, Kremer M, Pham R, DownsHolmes C, Sattar A, et al. Neglecting to screen women between 40 and 49 years old with mammography: what is the impact on treatment morbidity and potential risk reduction? AJR Am J Roentgenol. 2014; 202(2):282-8.

13. Siegel RL, Miller KD, Jemal A. Cancer statistics, 2016. CA Cancer J Clin. 2016; 66(1):7-30.

14. Albrecht CA, Amorim MH, Zandonade E, Viana $\mathrm{K}$, Calheiros J. Breast cancer mortality among patients attending a cancer hospital, Vitoria, ES. Rev Bras Epidemiol. 2013; 16(3):582-91.

15. Smith RA, Brooks D, Cokkinides V, Saslow D, Brawley OW. Cancer screening in the United States, 2013: a review of current American Cancer Society guidelines, current issues in cancer screening. CA Cancer J Clin. 2013; 63(2):88-105.

16. Renck DV, Barros F, Domingues MR, Gonzalez MC, Sclowitz ML, Caputo EL, et al. Equity in access to breast cancer screening in a mobile mammography program in southern Rio Grande do Sul State, Brazil. Cad Saúde Pública. 2014; 30(1):88-96.

17. Leite MF, Vitta FCF, Carnaz L, Conti MHS, Marta $\mathrm{SN}$, Gatti MAN, et al. Knowledge and practice of women regarding cervical cancer in a primary health care unit. Rev Bras Crescimento Desenvolv Hum. 2014; 24(2):208-13. 